DOI: 10.35621/23587490.v6.n3.p23-44

\title{
AVALIAÇÃO DE BLOCOS PARA PAVIMENTO INTERTRAVADO COM SUBSTITUIÇÃO PARCIAL DO AGREGADO MIÚDO POR RESÍDUOS CERÂMICOS
}

EVALUATION OF BLOCKS TO INTERLOCKING PAVEMENT WITH PARTIAL REPLACEMENT OF CERAMIC WASTE FINE AGGREGATE

Evila Mayara da Silva Souza ${ }^{1}$

Thalita Maria Ramos Porto ${ }^{2}$ Guilherme Urquisa Leite ${ }^{3}$ Hellykan Berliet dos Santos Monteiro ${ }^{4}$ Fernando Chagas de Figueiredo Sousa ${ }^{5}$ Maria Aparecida Bezerra Oliveira ${ }^{6}$ 
RESUMO: Objetivo: Elaborou-se um trabalho visando a um método alternativo para a confecção de blocos intertravados com características sustentáveis. Metodologia: Para a fabricação desses blocos, foi estudada experimentalmente a viabilidade técnica de se utilizarem os resíduos cerâmicos da construção e demolição (RCD) em substituição parcial ao agregado miúdo natural (areia), por ele vir se tornando cada vez mais escasso, pertinente ao esgotamento de jazidas, assim como as limitações dos órgãos ambientais para a extração da matéria-prima. $O$ trabalho visa também à reciclagem e à reutilização de resíduos descartáveis no meio ambiente, mostrando todo processo de caracterização dos materiais, detalhando cada etapa da produção, desde a coleta até a fase da utilização como agregado miúdo e todas as porcentagens das substituições $(0 \%, 10 \%, 20 \%, 30 \%)$ ao agregado natural, mantendo-se o mesmo fator água/cimento. Foram realizados ensaio de análise dimensional, absorção e resistência à compressão. Resultados: notou-se que a utilização do resíduo cerâmico na fabricação dos blocos intertravados diminui o teor de umidade e aumenta a resistência a cada teor de porcentagem adicionada. Conclusão: garante-se um material resistente, sustentável ao reutilizar os resíduos da construção e demolição (RCD) como agregado, e com isso, minimiza-se a utilização do agregado convencional e reduz-se o custo do material final.

Descritores: Pavimento. Bloco. Sustentabilidade. Resistência.

ABSTRACT: Objective: This work was developed seeking an alternative method for the manufacture of blocks interlocked with sustainable features. Methodology: For the manufacture of these blocks, the technical feasibility of using the ceramic waste from construction and demolition (WCD) was studied experimentally in partial replacement to natural fine aggregate (sand), for it has been becoming increasingly scarce, relevant to the exhaustion of deposits, as well as the limitations of environmental agencies for the extraction of raw materials. The work also aims at recycling and reusing disposable waste on the environment, showing the whole process of characterization of materials, detailing every step of production, since the collection up to the stage of household use as a fine aggregate and all the percentages of replacements $(0 \%, 10 \%, 20 \%, 30 \%)$ to natural aggregate, maintaining the same factor water/cement. Tests were performed (dimensional analysis, absorption and resistance to compression). Results: The use of ceramic waste in the manufacture of interlocked blocks reduces the moisture content and increases the resistance to each gross percentage added. Conclusion: It ensures a durable material, sustainable to reuse the waste from construction and demolition (WCD) as household, thus minimizing the use of conventional aggregate and reducing the cost of the final material.

Descriptors: Floor. Block. Sustainability. Resistance. 


\section{INTRODUÇÃO}

Os blocos intertravados são aplicados nas áreas de pavimentação como uma metodologia eficiente na construção. Devido à grande utilização do pavimento intertravado aqui no Brasil, a produção desses blocos aumenta a cada ano, decorrente principalmente da sua facilidade de execução, manutenção e resistência mecânica. De maneira paralela ao desenvolvimento e à crescente utilização de pavimentos intertravados, sabemos que, por uma série de razões, a utilização de resíduos pela indústria da construção civil está se tornando cada vez mais importante (FIORITI et al., 2010).

Devido ao setor da construção civil ser um dos maiores consumidores de matérias-primas naturais e geradores de resíduos sólidos, existem vários estudos que visam a explorar outros meios para substituir esses agregados naturais de forma sustentável. Levando em consideração que a geração dos resíduos da construção e demolição (RCD) é inevitável, devemos procurar um meio de desenvolver a sustentabilidade realizando um gerenciamento adequado dos materiais, reduzindo, reutilizando e reciclando, assim amenizando os impactos ambientais. Pensando nisso, uma das alternativas para minimizar a utilização da areia natural é a reutilização dos resíduos de classe $\mathrm{A}$, pelo fato de esse material estar se tornando cada vez mais escasso devido ao esgotamento de jazidas. $\mathrm{Na}$ resolução 307 do CONAMA, os RCDs são classificados de acordo com as possibilidades de reciclagem, recebendo o beneficiamento adequado para ser reutilizado como agregados, reduzindo o consumo da areia, gerando, assim, benefícios ao meio ambiente.

Mediante o exposto, o presente trabalho surge com o objetivo de produzir blocos intertravados, onde será substituída parcialmente a areia natural pelos resíduos cerâmicos. Todos os métodos para a fabricação dos blocos terá como norte a NBR 9781:2013 - Peças de concreto para pavimentação - Especificação e métodos de ensaios. 


\section{METODOLOGIA:}

O presente trabalho constituiu-se inicialmente de um estudo bibliográfico em outros trabalhos já desenvolvidos com a temática apresentada. A pesquisa é do tipo aplicada, qualitativa, explicativa e experimental, devido a sua abordagem se tratar de analisar uma substituição parcial do agregado miúdo natural pelos resíduos cerâmicos para a fabricação de blocos intertravados, através de métodos de ensaio, com intuito de gerar conhecimentos e solucionar problemas específicos. Para produção dos blocos intertravados, realizou-se a caracterização dos materiais a serem utilizados.

O aglomerante hidráulico aplicado para a fabricação dos blocos é o cimento Portland composto CP II E-32-RS, da marca Mizu cimentos, de acordo com a NBR11578. Sua composição é de silicato de cálcio, alumínio e ferro, sulfato de cálcio, filier carbonático e material pozolânico.

O agregado miúdo utilizado é areia natural média disposta no Laboratório de Matérias e Técnicas Construtivas da Faculdade Santa Maria (FSM), onde foram submetidos aos ensaios de composição granulométrica, massa especifica, massa unitária e o teor de umidade. Todos esses processos de ensaios também foram realizados para o material reciclado (resíduos cerâmicos). Depois desses ensaios, os materiais foram passados para a fabricação dos blocos. Todos os métodos de ensaios foram realizados no Laboratório de Materiais e Técnicas Construtivas da FSM.

Posteriormente, realizou-se o ensaio de granulometria e a disposição das partículas do agregado, podendo, assim, definir sua dimensão máxima (Dmáx) e o módulo de finura (MF), onde todos os processos foram realizados de acordo com a NBR - 7217/1987 (Agregados - Determinação da composição granulométrica).

Inicialmente, coletou-se e pesou-se uma amostra de $500 \mathrm{~g}$ do agregado conforme especificado na NBR-7217/1987, sendo, em seguida, colocada na estufa a 
uma temperatura de $110^{\circ} \mathrm{C}$. Após a secagem, deixou-se em temperatura ambiente e esperou-se que esfriasse.

Posteriormente, foram encaixadas as peneiras em ordem crescente de acordo com as respectivas aberturas de 4,75 mm - 2,0 mm - 1,18 mm - 0,600 mm - 0,250 $\mathrm{mm}-0,150 \mathrm{~mm}$ e o fundo.

Adicionou-se o agregado aos poucos no agrupamento das peneiras, para minimizar a aglomeração do material e agitado mecanicamente com ajuda do agitador eletromagnético de perneiras por $2 \mathrm{~min}$ para separar e classificar os diferentes diâmetros. Após a agitação, retirou-se camada por camada das peneira para definir a massa retida de cada uma delas. A figura 16 mostra o material retido em cada uma das peneiras.

Para definir o Dmáx, calculou-se a porcentagem da massa retida em cada peneira, e após isso, determinou-se a dimensão máxima característica ao que apresentou diâmetro $\leq$ a 5\%. Para a caracterização do módulo de finura do agregado (MF), calculou-se utilizando a fórmula 1.

(Fórmula 1 - Módulos de finura).

Onde:

MF = Módulo de finura;

$\mathrm{Mr}=$ Massa retida

De acordo com a NBR 6502/95, o diâmetro limite para o agregado miúdo (areia) é de $0,06 \mathrm{~mm}$ a 2,0 $\mathrm{mm}$, sendo classificadas em areia fina com granulometria de $0,06 \mathrm{~mm}$ a $0,20 \mathrm{~mm}$, areia média entre $0,20 \mathrm{~mm}$ e 0,60 $\mathrm{mm}$ e areia grossa 0,60 a 2,0. Como areia utilizada para a fabricação dos blocos é do tipo média, só será utilizado o material retido nas peneiras $0,600 \mathrm{~mm}$ e $0,250 \mathrm{~mm}$.

Para a realização do ensaio, utilizou-se como referência a NBR 9776:1987 (Agregados - Determinação de massa específica Chapman). Pesou-se inicialmente uma quantidade de $500 \mathrm{~g}$ do agregado (areia média); logo após a pesagem, foi inserida água até a demarcação exigida pela do frasco Chapman $200 \mathrm{~cm}^{3}$, deixandoo em descanso, para o escorrimento total da água. Em seguida, adicionou-se o 
agregado cuidadosamente no recipiente, sempre fazendo movimentos visando a evitar que as bolhas de ar se integrem no composto. Depois de inserir todo o material no frasco, esperam-se alguns minutos para a mistura sedimentar.

O cálculo da massa especifica do agregado será definida pela fórmula 2 abaixo:

Onde:

$\mathrm{Y}=$ massa específica do agregado miúdo $\left(\mathrm{g} / \mathrm{cm}^{3}\right)$;

$\mathrm{L}=$ leitura do frasco (volume ocupado pelo conjunto água-agregado miúdo) $\left(\mathrm{cm}^{3}\right)$.

Realizou-se esse mesmo processo duas vezes com a mesma amostra do agregado para verificar a diferença de um ensaio para o outro, não podendo diferir entre si mais de $0,05 \mathrm{~g} / \mathrm{cm}^{3}$.

De acordo com a NBR NM 45/2006, para determinar a massa unitária do agregado, é estabelecida uma relação entre a massa do agregado lançado no recipiente e o volume desse recipiente. Volume de vazios é o espaço entre os grãos de uma massa de agregado. Essa norma designa três técnicas de ensaios para determinar a massa unitária de material compactado (A, B e C), descritas na Tabela 1.

Tabela 1 - Métodos de ensaios de massa unitária.

\begin{tabular}{cl}
\hline A & Dmáx $37,5 \mathrm{~mm}$ \\
\hline B & Dmáx $37,5 \mathrm{~mm}$ \\
\hline C & É feito quando o material se encontra no seu estado solto.
\end{tabular}

Fonte: Adaptada da NBR NM 45 (2006), pelo autor (2019).

Pelo fato de o agregado encontrar-se no seu estado solto, o ensaio foi realizado de acordo com o método $C$, seguidos todos os critérios da NBR NM $45 / 2016$, onde foi definida a massa do recipiente vazio $\mathrm{mr}=0,460 \mathrm{~kg}$, seu volume $\mathrm{V}$ 
$=0,011 \mathrm{~m}^{3}$. Em seguida, em uma altura de aproximadamente $5 \mathrm{~cm}$, preencheu-se com 0 agregado até transbordar, com ajuda de uma concha. Após esse procedimento, nivelou-se a camada superficial do agregado com uma régua metálica, para ser colocado na balança, obtendo a massa da correlação recipienteagregado (Figura 18), para areia mar $=16,015 \mathrm{~kg}$, para o RCD mar $=14,010 \mathrm{~kg}$. Após isso, calculou-se a massa unitária do agregado pela fórmula 3 :

Onde:

ap = massa unitária do agregado $\left(\mathrm{Kg} / \mathrm{m}^{3}\right)$;

mar = massa do recipiente mais agregado $(\mathrm{Kg})$;

$\mathrm{mr}=$ massa do recipiente vazio $(\mathrm{Kg})$;

$=$ volume do recipiente $\left(\mathrm{m}^{3}\right)$.

Esse teor é expresso pela relação percentual entre a massa total de água que envolve a superfície e preenche os poros permeáveis do agregado e sua massa seca (NBR 9939, 1987).

Esse ensaio foi realizado pelo método da estufa, com quatro cápsulas para cada agregado (ilustrado na Figura 19), por ser um método mais preciso, seguindo todas as técnicas descritas na NBR 6457/86, onde foi obtido através da secagem das amostras por um período de 24 horas, com a temperatura constante de $105^{\circ} \mathrm{C}$. Realizou-se uma média de todos os pesos e substituindo-se na seguinte equação.

Para definir a umidade $h$, com relação ao peso seco, aplicou-se a fórmula 4:

Onde:

$\mathrm{h}=$ teor de umidade em relação ao peso seco (\%);

m1 = média do peso inicial do agregado úmido $(\mathrm{g})$.

$\mathrm{m} 2$ = média do peso final do agregado seco $(\mathrm{g})$. 
m3 = média do peso das cápsulas secas $(\mathrm{g})$.

O RCD que foi utilizado para a substituição parcial do agregado miúdo (areia) foram os resíduos cerâmicos de classe A (tijolos, blocos e telhas) como mostra na figura 20/a, recolhidos no deposito da madeireira piranhense da cidade de Cajazeiras/PB. Todos os resíduos reciclados tiveram beneficiamento, onde foram selecionados, em seguida, quebrados à mão com auxílio de uma marreta, deixando o resíduo com diâmetro menos. Posteriormente, inseriu-se o material na máquina de abrasão "Los Angeles", disposto no Laboratório de Materiais e Técnicas Construtivas da FSM para fazer esse trituramento. Como exposto na norma DNER-ME 035/98, de acordo com o diâmetro do resíduo, ficou na graduação G, programado em 500 voltas, e com 12 esferas, até chegar o mais próximo possível do agregado convencional, após essa tritura, os resíduos foram passado na peneira $4,75 \mathrm{~mm}$, para deixar todos na granulometria de agregado miúdo.

De acordo com pesquisas de trabalhos semelhantes, adotou-se como base 0 mesmo traço abordado no trabalho de conclusão de curso (Cardoso, 2016) que também relata uma substituição parcial do agregado miúdo para a fabricação de blocos intertravados. O traço que foi utilizado como base confecciona 36 blocos, seis blocos para cada substituição, e assim possuindo as seguintes proporções descrita na Tabela 2.

Tabela 2 - Traço base.

\begin{tabular}{cccc}
\hline Quantidade de blocos & Cimento & Agregado & Água \\
\hline 36 & $10 \mathrm{~kg}$ & $36 \mathrm{~kg}$ & $4,6 \mathrm{~L}$ \\
\hline 6 & $1,70 \mathrm{~kg}$ & $9 \mathrm{~kg}$ & $800 \mathrm{ml}$ \\
\hline
\end{tabular}

Fonte: Adaptada de Cardoso (2016), pelo autor (2019).

Após um teste utilizando o traço base para a fabricação dos blocos, observouse que o traço não ficou com características favoráveis em relação à mistura, havendo a necessidade de fazer algumas alteração no traço. Analisando os ensaios de caracterização dos agregados, e testado alguns traços, e com isso ficou definido o traço 1:2, como mostra a tabela 3. 
Tabela 3 - Traço para a fabricação dos blocos.

\begin{tabular}{cccc}
\hline Quantidade de blocos & Cimento & Agregado & Água \\
\hline $\mathbf{3 6}$ & $20,16 \mathrm{~kg}$ & $40,32 \mathrm{~kg}$ & $9,6 \mathrm{~L}$ \\
\hline $\mathbf{6}$ & $5,040 \mathrm{~kg}$ & $10,08 \mathrm{~kg}$ & $2,4 \mathrm{~L}$ \\
\hline
\end{tabular}

Fonte: Autor (2019).

A definição da porcentagem da substituição do resíduos da construção e demolição $(R C D)$ pelo agregado convencional (areia) foram as seguintes: (Tabela 4).

Tabela 4 - Porcentagem de substituição do RCD.

\begin{tabular}{cc}
\hline Traços & Quantidade de RCD em substituição à areia \\
\hline $\mathbf{1}$ & $0 \%$ de RCD \\
\hline $\mathbf{2}$ & $10 \%$ de RCD \\
\hline $\mathbf{3}$ & $20 \%$ de RCD \\
\hline $\mathbf{4}$ & $30 \%$ de RCD \\
\hline
\end{tabular}

Fonte: Autor (2019).

Após decidir a porcentagem da substituição do RCD pela areia, calculou-se o valor dos traços 2, 3 e 4 . Na tabela 5 , são retratados todos os traços utilizado para a fabricação dos blocos intertravados.

Tabela 5 - Quantidade de material para cada traço.

\begin{tabular}{ccccc}
\hline Traços & Cimento & Areia & RCD & Água \\
\hline $\mathbf{1}$ & $5,040 \mathrm{~kg}$ & $10,08 \mathrm{~kg}$ & - & $2,4 \mathrm{~L}$ \\
\hline $\mathbf{2}$ & $5,040 \mathrm{~kg}$ & $9,072 \mathrm{~kg}$ & $1,008 \mathrm{~kg}$ & $2,4 \mathrm{~L}$ \\
\hline $\mathbf{3}$ & $5,040 \mathrm{~kg}$ & $8,064 \mathrm{~kg}$ & $2,016 \mathrm{~kg}$ & $2,4 \mathrm{~L}$ \\
\hline $\mathbf{4}$ & $5,040 \mathrm{~kg}$ & $7,056 \mathrm{~kg}$ & $3,024 \mathrm{~kg}$ & $2,4 \mathrm{~L}$ \\
\hline
\end{tabular}

Fonte: Autor (2019).

A fabricação dos blocos intertravados foi realizada no Laboratório de Matérias e Técnicas Construtivas da Faculdade Santa Maria. As formas utilizadas para a produção dos corpos de prova são do formato retangular do tipo I (Figura 21), 
atendendo todas as exigências estabelecidas pela NBR 9781/2013, com as seguintes medições $20 \mathrm{~cm} \times 10 \mathrm{~cm} \times 5 \mathrm{~cm}$.

Primeiramente, foram pesados todos os matérias com a quantidade especificada na tabela 5 para os referentes traços. Em seguida, preparou-se mecanicamente a mistura dos agregados com o cimento com auxílio da betoneira, a fim de deixar a mistura homogênea, após isso, sendo incorporada aos poucos a água, até formar uma massa.

Antes de as formas receberem essa massa, adicionou-se desmoldante (desmol vg), para facilitar a retirada dos blocos, em seguida, as formas foram preenchidas manualmente com a mistura, e logo após retirados da forma, e assim produzindo os corpos de prova.

Todos os procedimentos de cura seguiram as diretrizes da NBR 5738:2003 (Concreto - Procedimento para moldagem e cura de corpos-de-prova).

O ensaio de análise dimensional trata-se da definição das dimensões (comprimento, largura e espessura) dos blocos. A avaliação dimensional das peças foi realizadaa em planos paralelos e perpendiculares às arestas das peças, conforme sua tipologia (NBR 9781, 2013).

Após, todas as medições, a NBR 9781:2013 fala que as tolerâncias dimensionais dos blocos podem ter $3 \mathrm{~mm}$ do valor efetivo. De acordo com as dimensões do bloco em pesquisa $(20 \mathrm{~cm} \times 10 \mathrm{~cm} \times 5 \mathrm{~cm})$, depois da análise dimensional, ele pode chegar no máximo à $20,3 \mathrm{~cm} \times 10,3 \mathrm{~cm} \times 5,3 \mathrm{~cm}$ e no mínimo $19,7 \mathrm{~cm} \times 9,7 \mathrm{~cm} \times 4,7 \mathrm{~cm}$. Foram analisados todos os blocos de cada traço para a realização desse ensaio. Após a fabricação dos blocos, aguardou-se um intervalo de 28 dias para a execução do experimento. Como a NBR 9781 não caracteriza o período de espera dos corpos de prova para o processo do ensaio, o tempo que será utilizado terá como fundamento o trabalho de Cruz (2013) com base na MB 3459. As peças devem apresentar absorção de água $6 \%$, não admitindo valor maior que $7 \%$.

Inicialmente, retirou-se todo o fragmento do bloco com a utilização de uma escova. Logo após essa limpeza, as peças foram submergidas em uma caixa de brasilit de 500 I com água por um período de 24 horas. Depois desse tempo, foram retirados todos os corpos de prova, secados com auxílio de uma toalha úmida e 
depois pesados na balança na situação saturada com superfície seca, registrando o valor da massa saturada $(\mathrm{m} 2)$ de cada peça. A segunda etapa correspondeu à secagem, onde os blocos foram levados para a estufa com uma temperatura $110 \stackrel{\circ}{\circ} \mathrm{C}$ por 24 horas, após esse prazo, retirou-se, pesou-se e obteve-se o valor da massa seca (m1) no máximo de tempo de 10 minutos.

Depois que todos os valores das massas foram coletados, a porcentagem de absorção da água é calculada pela seguinte fórmula 5:

Para a execução do ensaio de compressão, foram utilizadas seis amostras de cada teor de substituição, onde foi aguardado o tempo de cura de 28 dias para a realização do mesmo. A máquina de resistência à compressão é do tipo classe 2. A resistência deve atender a NBR 9781:2013, como mostra o Quadro 3.

Quadro 3 - Resistência característica à compressão.

Devido à máquina de ensaio de compressão ser com pratos cilíndricos, fabricou-se uma chapa retangular (Figura 29/b) com as mesmas dimensões dos blocos para que a resultante das força passe pelo centro da peça. Antes de começar o ensaio, os blocos estavam saturados 24 horas antes em água, e as superfícies de carregamento retificadas (NBR 9781, 2013), para então instalar o corpo de prova no maquinário, com um carregamento continuo até a sua ruptura.

\section{RESULTADOS:}

A partir do ensaio de composição granulométrica realizado no laboratório de materiais e técnicas construtivas da faculdade Santa Maria, determinaram-se os 
seguintes valores retidos em cada peneira e o retido acumulado, exposto na tabela abaixo:

Tabela 6 - Limites granulométricos para os agregados.

Fonte: Autor (2019).

Após a obtenção dos valores da granulometria dos agregados miúdos (areia e RCD), realizou-se a curva de distribuição granulométricas para a determinação geral de suas características físicas, conforme os Gráficos 1 e 2.

Gráfico 1 - Curva granulométrica da areia.

Fonte: Autor (2019). 
Gráfico 2 - Curva granulométrica do resíduo cerâmico.

Fonte: Autor (2019).

Com os dados coletados, podemos definir o diâmetro máximo e o módulo de finura dos agregados. Como a norma especifica que o diâmetro máximo tem que ser inferior a $5 \%$ da porcentagem retida, de acordo com os resultados apresentados na tabela 6, determinou-se o diâmetro máximo (Dmáx) dos agregados. Para a areia, foi de $0,150 \mathrm{~mm}$, e para os resíduos cerâmicos, foi de $4,750 \mathrm{~mm}$.

Para a determinação do módulo de finura (MF), utilizou-se a fórmula 1 do somatório das porcentagem retidas acumuladas e dividido por 100 , dando os seguintes resultados. Para areia 2,596 e para os resíduos cerâmicos 2,416. Conforme realizado no ensaio, pode-se perceber que o RCD é mais fino com granulometria menor que a agregado convencional, quando analisado na mesma quantidade, ou seja, quando utilizado esse resíduo com quantidade significativa, vai interferir na trabalhabilidade da mistura, pois tem uma maior capacidade de absorção em relação areia natural. A partir desses dados, foi possível caracterizar os dois agregados de granulometria média, pois a NBR 7211 diz que o agregado médio encontra-se entre 3,30 > M.F. > 2,40. 
Tabela 7 - Determinação da massa específica.

Fonte: Autor (2019).

Com esses resultados, podemos comprovar que, de acordo com a mesma quantidade de material analisado, a massa especifica do resíduo cerâmico é menor que a da areia, desconsiderando os vazios existentes. Conforme já visualizado no ensaio de granulometria e de caracterização do módulo de finura, o resíduo cerâmico é um material que absorve mais rápido por ser mais fino que o agregado convencional. Esses valores são importantes, pois irão influenciar na dosagem do traço, na trabalhabilidade da mistura e no resultado final dos blocos intertravados.

Tabela 8 - Resultados da massa unitária dos agregados.

Fonte: Autor (2019).

De acordo com as especificações da NBR NM 45/2016, podemos coletar os dados primeiramente do volume do recipiente, $V=0,011 \mathrm{~m}^{3}$. Sabendo-se desse volume, obtivemos os valores escrito na tabela 8 .

A partir dos resultados coletados em estufa a uma temperatura de $105^{\circ} \mathrm{C}$, após 24 horas, obtiveram-se os seguintes valores estabelecidos na tabela 9. 
Tabela 9 - Teor de umidade.

Fonte: Autor (2019).

De acordo com os valores obtido na tabela 9, realizou-se uma média de todos os pesos e substituído na fórmula 3 . Com os respectivos resultados, para a areia $0,711 \%$, e para os resíduos cerâmicos $0,569 \%$. Como essa porcentagem de umidade, é possível fazer a correção do volume dos agregados, devido à possibilidade de inchamento.

O resultado da umidade encontrada no resíduo cerâmico foi menor, por ele possuir uma dimensão menor que o material convencional, sendo um material fino por ter uma granulometria menor, ou seja, sua área de contato é menor, garantindo menos capacidade de absorção.

O ensaio de absorção dos blocos foi realizado conforme estabelecido na NBR 9781 (2013) para os blocos com 28 dias de cura. A Tabela 11 apresenta os valores das massas e da porcentagem de absorção para cada tipo de bloco, sendo calculada pela fórmula 5 . 
Tabela 11 - Absorção dos blocos intertravados

Fonte: Autor (2019).

Com os dados obtido no Gráfico 3, pode-se perceber que quanto mais se adicionavam resíduos cerâmico nos blocos intertravados, o teor de absorção diminuía. Isso ocorre devido ao poder de absorção que o RCD apresenta, como já exposto nos ensaios de caracterização dos materiais, por possuir menor granulometria e módulo de finura com relação ao agregado convencional, ou seja, por ele ser uma material fino, atuando no preenchimento dos poros, proporcionando mais aderência na mistura, diminuindo os espaços vazios, e favorecendo no menor índice de absorção.

Gráfico 3 - Absorção dos blocos com 28 dias.

Fonte: Autor (2019). 
O ensaio de resistência à compressão é imprescindível para garantir um controle de qualidade e segurança da peça. Os valores apresentados na Tabela 12 foram obtidos pela fórmula 6 , onde a média da área do bloco foi resultado do ensaio de análise dimensional, e o fator dado pela espessura do bloco.

(Fórmula 6 - Tensão admissível).

Tabela 12 - Valores de resistência à compressão dos blocos.

\begin{tabular}{|c|c|c|c|c|c|c|c|c|c|}
\hline ÁRE A $\left(\mathrm{mm}^{2}\right)$ & BLOCOS & FORC̣A (N) & TE NSÃO (Mpa) & FORCุA (N) & TE NSÃO(Mpa) & FORC̣A (N) & TENSÃO(Mpa) & FORÇA (N) & TENSÃO(Mpa) \\
\hline 19780,56 & & \multicolumn{2}{|c|}{$0 \%$} & \multicolumn{2}{|c|}{$10 \%$} & \multicolumn{2}{|c|}{$20 \%$} & \multicolumn{2}{|c|}{$30 \%$} \\
\hline FAT OR $\rho$ & $\mathrm{Bl}$ & 557017,72 & 28,16 & 557017,72 & 28,16 & 562901,71 & 28,46 & 557017,72 & 28,16 \\
\hline \multirow[t]{6}{*}{1} & $\mathrm{~B} 2$ & 557017,72 & 28,16 & 500139,15 & 25,28 & 586437,67 & 29,65 & 649200,23 & 32,82 \\
\hline & $\mathrm{B} 3$ & 474641,86 & 24,00 & 531520,43 & 26,87 & 570747,03 & 28,85 & 621741,61 & 31,43 \\
\hline & B4 & 496216,49 & 25,09 & 498177,82 & 25,19 & 527597,77 & 26,67 & 574669,69 & 29,05 \\
\hline & B6 & 496608,76 & 25,11 & 509945,8 & 25,78 & 558979,05 & 28,26 & 609973,63 & 30,84 \\
\hline & B6 & 509945,8 & 25,78 & 513868,46 & 25,98 & 535443,09 & 27,07 & 615857,62 & 31,13 \\
\hline & Média & 515241,39 & 26,05 & 518444,90 & 26,21 & 557017,72 & 28,16 & 604743,42 & 30,57 \\
\hline
\end{tabular}

Fonte: Autor (2019).

Conforme os dados obtidos, pode-se perceber que, quanto maior o teor de substituição do agregado natural (areia) pelo agregado reciclado, maior resistência admissível à compressão do bloco intertravado. Ou seja, o resíduo cerâmico é significativamente alterado pela composição da adição/substituição, tornando-se um material mais resistente, quando comparado ao agregado convencional. Após encontrar a resistência admissível à compressão, aplica-se na Fórmula 7 para encontrar a resistência característica à compressão. Com os seguintes valores apresentado no Gráfico 4.

(Fórmula 7 - Resistência característica). 
Gráfico 4 - Resistência característica à compressão.

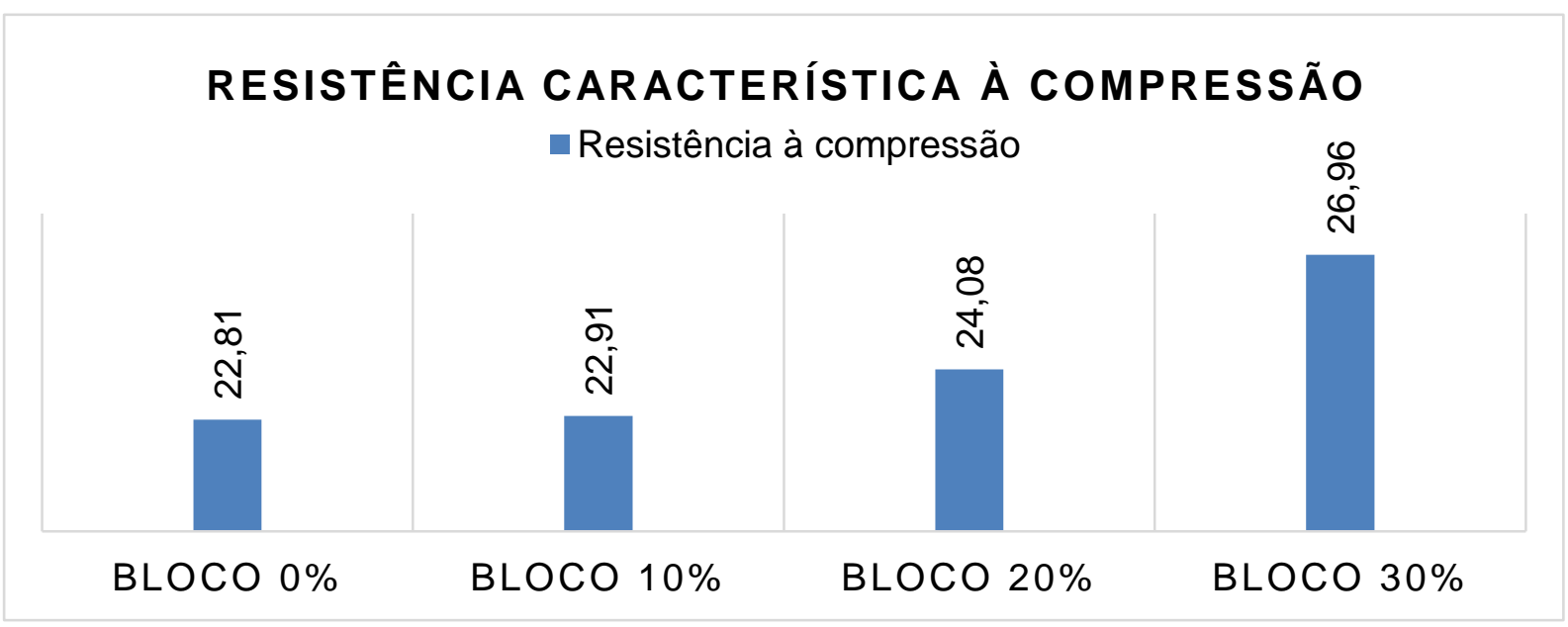

Fonte: Autor (2019).

Em conformidade com o Gráfico 4, a resistência característica aumenta a cada porcentagem adicionada/substituída no bloco. Isso ocorre no desenvolvimento do efeito pozolânico por parte dos resíduos cerâmicos e pela existência das partículas finas de argila no material. De acordo com Paixão (2013), a granulometria mais contínua e a maior quantidade de finos apresentada pelo agregado reciclado ajudam no efeito empacotamento e contribuem para o fechamento dos vazios.

\section{CONCLUSÃO}

Realizou-se uma pesquisa sobre a influência dos resíduos cerâmicos como substituição parcial ao agregado miúdo (areia), para a fabricação de blocos intertravados, a fim de possuir um material sustentável e que atendesse a todas as exigências que a NBR 9781:2013 (Peças de concreto para pavimentação Especificações e métodos de ensaios) estabelece. Foram analisados nos quesitos de análise dimensional, absorção e resistência a compressão de todos os 36 blocos fabricados, com teores de substituição de $0 \%, 10 \%, 20 \%$ e $30 \%$ da areia média por resíduos da construção e demolição de classe A (resíduos cerâmicos).

Através dos ensaios realizados, foi possível ter os seguintes resultados: 
- Para o ensaio de análise dimensional, atendeu todos os parâmetros que a norma estabelece, com uma média das seguintes características comprimento, largura e espessura, respectivamente: $0 \%-19,92 \times 9,93 \times 4,95 ; 10 \%$ $19,93 \times 9,92 \times 4,9 ; 20 \%-19,91 \times 9,91 \times 4,91 ; 30 \%-19,95 \times 9,98 \times 4,96$.

- Com relação à absorção dos blocos, atenderam parcialmente às exigências que a norma recomenda. O bloco com 30\% de substituição foi o único que passou com a porcentagem menor que $6 \%$, já os blocos com $0 \%$ e $20 \%$ ficaram acima de $6 \%$, mas não ultrapassaram os $7 \%$; apenas o de $10 \%$ que não atendeu a NBR.

- A resistência à compressão foi aumentando de acordo com a quantidade de teor de substituição adicionado, mas não atendeu as determinações que norma solicita. A compactação pode ter sido um dos fatores que influenciaram nessa baixa resistência, devido a não ter sido compactado com a mesma eficiência que a vibro prensa industrial produz.

Em decorrência desses ensaios, podemos concluir que os blocos intertravados com a substituição parcial do resíduo cerâmico produzido manualmente influencia diretamente na absorção e resistência do bloco analisado, obtendo um menor índice de absorção, estando parcialmente nas porcentagem que a norma estabelece. Já no ensaio de resistência, a compressão obteve maior resistência quando comparado com o bloco convencional, mas não atendeu à solicitação da NBR 9781/13.

De forma geral, conclui-se que, com base nas características estudada, o uso do resíduo cerâmico é viável para produção de blocos intertravados. No entanto, é importante ressaltar que a resistência pode não ter sido atendida em relação ao que a norma estabelece, devido à compactação manual não ser tão eficiente quanto ao da vibro prensa industrial.

Por fim, destaca-se que, apesar do bom comportamento apresentado pela utilização de resíduos cerâmicos para a fabricação de blocos intertravados, outros estudos devem ser realizados com o objetivo de confirmar os resultados apresentado na pesquisa. Além disso, devem ser consideradas outras sugestões de trabalhos futuros, para dar continuidade à pesquisa. Pode-se realizar um estudo avaliativo com outros teores de substituição; analisar e comparar o custo de um 
material reciclado com beneficiamento, implantando técnicas para fabricação de novos materiais sustentáveis.

\section{REFERÊNCIAS BIBLIOGRÁFICAS}

ÂNGULO, S. C.; ZORDAN, S. E.; JOHN, V. M. Desenvolvimento sustentável e a reciclagem de resíduos na construção civil. PCC - Departamento Engenharia de Construção Civil da Escola Politécnica. Anais. São Paulo, 2001.

ARAÚJO, Paulo Roberto de; TUCCI, Carlos E. M.; GOLDENFUM, Joel A. Avaliação da eficiência dos pavimentos permeáveis na redução de escoamento superficial. Porto Alegre - Rs. p.1-8, abr. 2010.

BERTOLETTI, André Gonçalves. Pavimentos permeáveis e sua influência sobre drenagem. Departamento de Engenharia Hidráulica e Ambiental - PHA da Escola Politécnica da Universidade de São Paulo, São Paulo-SP, 2014.

BOTELHO, M. H. C. Concreto armado, eu te amo, para arquitetos. São Paulo: Edgard Blucher, 2006, p. 34.

BRASÍLIA PAVER, Assentamento de piso intertravado. Disponível em: $<$ https://www.brasiliapaver.com.br/produtos/piso-intertravado-bloquete/>. Acesso em $17 \mathrm{de}$ março de 2019.

BUEST NETO, Guilherme Teodoro. Estudo da substituição de agregados miúdos naturais por agregados miúdos britados em concretos de cimento portland. Dissertação (Mestrado) - Curso de Construção Civil, Universidade Federal do Paraná, Curitiba, 2006.

CARDOSO, Narawilka. Influência da adição do pó de pedra na absorção de água em blocos utilizados em pisos intertravados. 2016. 71 f. TCC (Graduação) - Curso de Engenharia Civil, Universidade Federal Rural do Semi-Árido - UFERSA, Caraúbas-RN, 2016.

CIMENTO MAUÁ, Piso intertravado: conheça suas características e benefícios. Disponível em: $\quad$ Lhttps://cimentomaua.com.br/blog/piso-intertravado-conheca-suas-caracteristicas-ebeneficios/>. Acesso em 30 de agosto de 2018 .

COUTO, J. A. S. et al. O concreto como material de construção. Cadernos de Graduação Ciências Exatas e Tecnológicas, Sergipe, p. 49-58, 2013.

DALDEGAN, Eduardo. ENGENHARIA CONCRETA, Piso Intertravado: aprenda como fazer e confira dicas importantes. Disponível em: < https://www.engenhariaconcreta.com/pisointertravado-aprenda-como-fazer-e-confira-dicas-importantes/>. Acesso em 30 de agosto de 2018.

DNER - ME 052 - Solos e agregados miúdos - Determinação da umidade com emprego do "Speedy", 1994.

ECO TELHADO, Pavimentação permeável. Disponível em: $<$ https://ecotelhado.com/pavimentacao-permeavel/>. Acesso em 18 de setembro de 2018. 
FILHO, K. Z. et al. Coleção Águas Urbanas - Fascículo 3: Inundações Urbanas. 21 f. Departamento de Engenharia Hidráulica e Ambiental - PHA da Escola Politécnica da Universidade de São Paulo, São Paulo-SP, 2012.

FIORITI, C. F.; AKASAKI, J. L.; INO, A. Fabricação de pavimentos intertravados de concreto utilizando resíduos de recauchutagem de pneus. XI Encontro Nacional de Tecnologia no Ambiente Construído, Florianópolis-SC, p. 4109-4117, 2006.

FIORITI, C. F.; INO, A; AKASAKI, J. L. Análise experimental de blocos intertravados de concreto com adição de resíduos do processo de recauchutagem de pneus. Acta Scientiarum. Technology, Maringá, v. 32, n. 3, p. 237-244, 2010.

FIORITI, Cesar Fabiano. Pavimentos Intertravados de Concreto Utilizando Resíduos de Pneu como Material Alternativo. 2007. 218f. Tese (Doutorado em Ciências da Engenharia Ambiental) - UNIVERSIDADE DE SÃO PAULO, São Carlos, 2007.

FRANÇA, E. A. et al. Blocos de concreto produzidos com agregados de resíduos de construção e demolição - RCD: Processo de produção. Jornada de Pesquisa e Extensão, Cuiabá-MG, 2013.

JOHN, V.M. Reciclagem de resíduos na construção civil. Contribuição à metodologia de pesquisa e desenvolvimento... 102 p. Tese de Doutorado - Escola Politécnica, Universidade de São Paulo. São Paulo, 2000.

LEI N 13.885 - Disciplina e ordena do uso e ocupação do solo. Prefeitura do município de São Paulo, AGO 2004.

LODI, Victor Hugo. Viabilidade técnica e econômica do uso de areia de britagem em concretos de cimento portland na região de chapecó-sc. 2006. 131 f. Dissertação (Mestrado) - Curso de Engenharia Civil, Universidade Federal de Santa Catarina, Florianópolis, 2006.

LYRA, Mário Limeira de. Blocos intertravados de concreto com resíduos de copolímero de etileno-acetato de vinila - eva - para pavimentação de calçadas e passeios públicos. Dissertação (Mestrado) - UFPB/CT - João Pessoa, 2007.

MAFRA, Leandro. Verificação da qualidade de peças de concreto para pavimento intertravado de indústrias de Brusque (SC), Centro Universitário de Brusque - UNIFEBE, p. 1-13, 2016.

MARCHIONI, Mariana Lobo. Desenvolvimento de técnicas para caracterização de concreto seco utilizado na fabricação de peças de concreto para pavimentação intertravada. 2012. 112 f. Dissertação (Mestrado) - Curso de Construção Civil, Escola Politécnica da Universidade de São Paulo, São Paulo - SP, 2012.

MEHTA, P. Kumar; MONTEIRO, Paulo J. M. Concreto: Microestrutura, propriedades e materiais. $2^{\mathrm{a}}$ Edição. São Paulo: IBRACON, 2014. $751 \mathrm{f}$.

MENDES, B. S.; BORJA, E. V. Estudo experimental das propriedades físicas de argamassas com adição de resíduos de cerâmicas vermelhas recicladas. Holos, Ano 23, Vol. 3, 2007.

METROLOGIA E MEDIÇÕES, Ensaio de compressão em corpos de prova de concreto. Disponível em: <https://metrologiaemedicoes.wordpress.com/2017/11/13/ensaio-decompressao-em-corpos-de-prova-de-concreto/>. Acesso em 28 de setembro de 2018.

MOREIRA, C.; MEDINA, A. P.; LOURENÇO, L. Estudo da substituição do agregado miúdo natural pelo resíduo da pedra de pirenopolis em concreto de cimento Portland, Revista 
Engenharia e Construção Civil, Curitiba-PR, p. 12-23, 2014.

NBR 15.575: Desempenho de edificações habitacionais, MAI 2013.

NBR 5738: Procedimento para moldagem e cura de corpos de prova, DEZ 2003.

NBR 5739: Concreto - Ensaio de compressão de corpos de prova cilíndricos, JUL 1994.

NBR 6502 - Rochas e solos, SET 1995.

NBR 7217: Agregados - Determinação da composição granulométrica. Rio de Janeiro, AGO 1987.

NBR 9776: Agregados - Determinação da massa específica de agregados miúdos por meio do frasco Chapman, MAR 1987.

NBR 9781: Peças de concreto para pavimentação - Especificação e métodos de ensaio, FEV 2013.

NBR NM 45 - Agregados - Determinação da massa unitária e do volume de vazios, $A B R$ 2006.

OLIVEIRA, J. C. Indicadores de potencialidades e desempenho de agregados reciclados de resíduos sólidos da construção civil em pavimentos flexíveis. Tese de Doutorado Departamento de Ciências - Universidade de Brasília. Brasília, 2007.

PAIXÃO, Suelen de Oliveira. Estudo do uso de resíduo cerâmico de obras como agregado miúdo para a fabricação de argamassas para revestimento de alvenarias. 2013. $74 \mathrm{f}$. TCC (Graduação) - Curso de Engenharia Civil. Escola Politécnica, Universidade Federal do Rio de Janeiro, Rio de Janeiro - RJ, 2013.

PRADO FILHO, J. F.; SOBREIRA, F. G. Desempenho operacional e ambiental de unidades de reciclagem e disposição final de resíduos sólidos domésticos financiadas pelo ICMS Ecológico de Minas Gerais. Engenharia Sanitária Ambiental. 12 (1), 52-61. Minas Gerais, 2007.

RESOLUÇÃO CONAMA № 307. Gestão dos resíduos da construção civil, JUL 2002.

SANTOS, Eder Carlos Guedes. Aplicação de resíduos de construção e demolição reciclados (RCD-R) em estruturas de solo reforçado. 2007. 168 f. Dissertação (Mestrado) Curso de Engenharia Geotécnica, Escola de Engenharia de São Carlos da Universidade de São Paulo, São Carlos-SP, 2007.

RODRIGUES, Públio Penna Firme. Boletim técnico: Fabricação de Blocos Pré-Moldados de Concreto para Pavimentação Prática Recomendada. São Paulo - Sp: Associação Brasileira de Cimento Portland, 1995.

SANTOS, K. A.; RUFINO, I. A. A.; FILHO, M. N. M. B. Impactos da ocupação urbana na permeabilidade do solo: 0 caso de uma área de urbanização consolidada em Campina Grande- PB, p. 943-952, 2017.

SILVEIRA, C. A.; DIAS, P.; SCHUCH, F. S. A problemática das inundações em áreas urbanas sob a ótima da permeabilidade do solo. Congresso Brasileiro de Cadastro Técnico Multifinalitário, Florianópolis-SC, 2014. 